\title{
A comparison of a model using the FORMOSAT-3/COSMIC data with the IRI model
}

\author{
Yoshihiro Kakinami ${ }^{1 *}$, Jann-Yenq Liu ${ }^{1,2}$, and Lung-Chih Tsai ${ }^{2}$ \\ ${ }^{1}$ Institute of Space Science, National Central University, No. 300 Jhongda Rd. Jhongli, Taoyuan 32001, Taiwan \\ ${ }^{2}$ Center for Space and Remote Sensing Research, National Central University, No. 300 Jhongda Rd. Jhongli, Taoyuan 32001, Taiwan
}

(Received August 18, 2010; Revised January 4, 2011; Accepted October 8, 2011; Online published July 27, 2012)

\begin{abstract}
In this study, an empirical model constructed using data of FORMOSAT3/COSMIC (F3/C) from 29 June, 2006, to 17 October, 2009, retrieves altitude profiles of electron density $\left(N_{\mathrm{e}}\right)$. The model derives global $N_{\mathrm{e}}$ profiles from 150 to $590 \mathrm{~km}$ altitude as functions of the solar EUV flux, day of year, local time and location under geomagnetically quiet conditions $\left(K_{\mathrm{p}}<4\right)$. $N_{\mathrm{e}}$ profiles derived by the model are further compared with those of the International Reference Ionosphere (IRI). Results show that the $F_{2}$ peak altitude $h_{\mathrm{m}} F_{2}$ and the electron density $N_{\mathrm{m}} F_{2}$, as well as the electron density above, derived by the model are lower than those of the IRI model. The F3/C model reproduces observations of F3/C well at $410-\mathrm{km}$ altitude while the IRI model overestimates them. The overestimation of the IRI model becomes large with decrease of EUV flux. It is found that the topside vertical scale height of the F3/C model shows high values not only magnetic dip equator but also middle latitude. The results differ significantly from those of IRI, but agree with those observed by topside sounders, Alouette and ISIS satellites.
\end{abstract}

Key words: IRI, electron density, topside ionosphere, empirical model, FORMOSAT-3/COSMIC, vertical scale height.

\section{Introduction}

The International Reference Ionosphere (IRI) has been developed since 1978 (Rawer et al., 1978) and is established as the most standard and reliable ionospheric empirical model. Since a large amount of ionosonde data has been used, IRI derives a relatively accurate electron density $\left(N_{\mathrm{e}}\right)$ profile below the $F_{2}$ peak. However, the IRI model might still have some shortcomings in the topside ionosphere, because very limited satellite data are included. Bilitza (2004) and Bilitza et al. (2006) based on Alouette/ISIS topside sounder observations reported that the IRI model overestimates $N_{\mathrm{e}}$ above the $F_{2}$ peak height. Furthermore, Kakinami et al. (2008) found an in-situ $N_{\mathrm{e}}$ observation at a $600-\mathrm{km}$ altitude with the Hinotori satellite which differed from the IRI $N_{\mathrm{e}}$. This shortcoming also results in a difference between the Total Electron Content (TEC) reproduction and real observations, because the TEC is calculated using an integration of the $N_{\mathrm{e}}$ profile. Meanwhile, the IRI model overestimates the TEC in the equatorial region (Bilitza and Williamson, 2000) during high solar activity, while the IRI model overestimates and underestimates the TEC over Taiwan $\left(24^{\circ} \mathrm{N} 120^{\circ} \mathrm{E}\right)$ during low and high solar activity, respectively (Kakinami et al., 2009).

*Now at Institute of Seismology and Volcanology, Hokkaido University, Kita 10 Nishi 8, Kita-ku, Sapporo 060-0810, Japan.

Copyright (c) The Society of Geomagnetism and Earth, Planetary and Space Sciences (SGEPSS); The Seismological Society of Japan; The Volcanological Society of Japan; The Geodetic Society of Japan; The Japanese Society for Planetary Sciences; TERRAPUB.

doi:10.5047/eps.2011.10.017
Six FORMOSAT-3/COSMIC (F3/C) micro satellites which constituted a global positioning system (GPS) occultation experiment (GOX) payload were launched on 14 April, 2006, and put into a low Earth orbit of $800-\mathrm{km}$ altitude with a $72^{\circ}$ inclination. An average of 1800 electron density profiles was obtained in a day globally. Lei et al. (2007) reported that $N_{\mathrm{e}}$ profiles measured with $\mathrm{F} 3 / \mathrm{C}$ are consistent with $N_{\mathrm{m}} F_{2}$ and $h_{\mathrm{m}} F_{2}$ obtained with incoherent scatter radars at Millstone Hill and Jicamarca. An $N_{\mathrm{e}}$ profile obtained using GOX has an advantage in its coverage of observations, compared with the peak density and peak altitude of the ionosphere obtained with ground-based observations, because it was able to cover ocean and desert areas, where there are usually no receivers. Taking advantage of this feature, we have constructed an empirical model of the $N_{\mathrm{e}}$ profile measured with $\mathrm{F} 3 / \mathrm{C}$, which reproduces the $N_{\mathrm{e}}$ profile globally. In this paper, we describe the methodology in constructing the model and compare the empirical model based on F3/C observations with the IRI model.

\section{Methodology of the Construction of an Empir- ical Model}

The methodology of constructing an empirical model based on F3/C data is described in this section. Henceforth, the empirical model based on $N_{\mathrm{e}}$ profiles obtained by $\mathrm{F} 3 / \mathrm{C}$ is referred to as the $\mathrm{F} 3 / \mathrm{C}$ model. The $\mathrm{F} 3 / \mathrm{C}$ model reproduces $N_{\mathrm{e}}$ as functions of the solar EUV flux, day of year (DOY), local time (LT), altitude and location. A similar methodology has been applied to empirical models of transition height (Marinov et al., 2004; Kutiev and Marinov, 2007), vertical scale height in the top- 
side ionosphere (Kutiev et al., 2006) and TEC over Taiwan (Kakinami et al., 2009). Daily EUV (0.1-50 nm) measured by the Solar Heliospheric Observatory (SOHO) (Judge et al., 1998) and posted on the web site of the Space Science Center of the University of Southern California (http://www.usc.edu/dept/space_science/), is used to construct the model. The released EUV fluxes are modified using the Sun-Earth distance because the released daily EUV fluxes are adjusted at $1 \mathrm{AU}$. Data are not used in the model construction when the EUV exceeds $10^{11}$ photon $/ \mathrm{cm}^{2} \mathrm{sec}$ due to a solar flare. The EUV variation used in the F3/C model, which is excluded the fluctuated day, is shown in Fig. 1. Observed $N_{\mathrm{e}}$ profiles are accumulated under geomagnetically quiet conditions $\left(K_{\mathrm{p}}<4\right)$ from 29 June, 2006, to 17 October, 2009. Since $N_{\mathrm{e}}$ profiles are calculated using the Abel inversion with an assumption of spherical symmetry, the errors mainly appear below $250 \mathrm{~km}$ around the equatorial ionization anomaly region (Liu et al., 2010), which leads to a negative value of the $N_{\mathrm{e}}$ profile in some cases. Therefore, observed $N_{\mathrm{e}}$ profiles showing a negative value are not used in the model construction. At first, the empirical model which has functions of EUV, DOY and LT is constructed in each 3-dimensional bin whose size is $30^{\circ}$ in longitude, $18^{\circ}$ in latitude and $20 \mathrm{~km}(40 \mathrm{~km})$ altitude between 150 and 390 (390 and 590) km altitude with steps of $10^{\circ}$ in longitude and $6^{\circ}$ in latitude. It is assumed that the solar flux variation of $\log _{10}\left(N_{\mathrm{e}}\right)$ is proportional to the EUV flux, while the DOY and LT variation of $\log _{10}\left(N_{\mathrm{e}}\right)$ are derived using a combination of trigonometric functions of wavenumbers 1-3 and 1-4, respectively. The modeled functions are calculated for each bin. The functions for F, DOY and LT are defined as follows:

$$
\begin{aligned}
f(\mathrm{EUV})= & a_{1}+a_{2} \mathrm{EUV} \\
g(\mathrm{DOY})= & b_{1}+\sum_{i=1}^{3}\left(b_{2 i} \cos 2 \pi i \cdot \mathrm{DOY}\right. \\
& \left.+b_{2 i+1} \sin 2 \pi i \cdot \mathrm{DOY}\right) \\
= & b_{1} g_{1}^{\prime}+\cdots+b_{7} g_{7}^{\prime}, \\
h(\mathrm{LT})= & c_{1}+\sum_{i=1}^{4}\left(c_{2 i} \cos \frac{\pi i \cdot \mathrm{LT}}{12}+c_{2 i+1} \sin \frac{\pi i \cdot \mathrm{LT}}{12}\right) \\
= & c_{1} h_{1}^{\prime}+\cdots+c_{9} h_{9}^{\prime},
\end{aligned}
$$

where $a, b, c$ are coefficients for fitting. DOY is normalized by the length of the year. The function reproducing $N_{\mathrm{e}}$ is assumed to be the product of these 3 functions. Then we can obtain:

$$
\begin{aligned}
\log _{10} N_{\mathrm{e}}(\mathrm{EUV}, \mathrm{DOY}, \mathrm{LT}) & =f(\mathrm{EUV}) \cdot g(\mathrm{DOY}) \cdot h(\mathrm{LT}) \\
& =\sum_{i, j, k} a_{i} f_{i}^{\prime} \cdot b_{j} g_{j}^{\prime} \cdot c_{k} h_{k}^{\prime} \\
& =\sum_{n=1}^{126} \alpha_{n} \log _{10} N_{\mathrm{e}_{n}^{\prime}}^{\prime}
\end{aligned}
$$

where $n=(i-1) \times 63+(j-1) \times 9+k, i=1,2$, $j=1, \ldots, 7, k=1, \ldots, 9$. In order to calculate the coefficients $\alpha$, more than 126 data are required. The $\alpha$ can be obtained by solving the following normal-equation

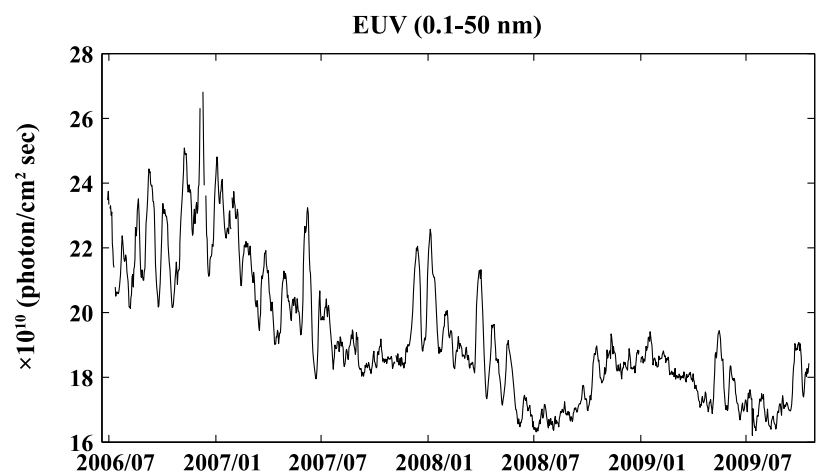

Fig. 1. EUV variation observed with SOHO from 29 June, 2006, to 17 October, 2009. Only data used in the construction of the F3/C model are shown.

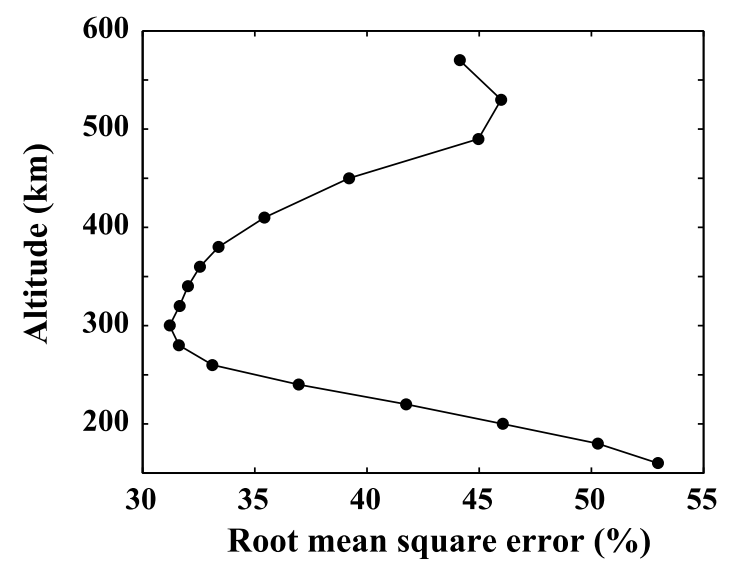

Fig. 2. Variation of root mean square error of the F3/C model with altitude.

matrix:

$\left(\begin{array}{c}\sum \log _{10} N_{\mathrm{e}} \cdot \log _{10} N_{\mathrm{e}_{1}^{\prime}}^{\prime} \\ \vdots \\ \sum \log _{10} N_{\mathrm{e}} \cdot \log _{10} N_{\mathrm{e}_{126}^{\prime}}^{\prime}\end{array}\right)$
$=\left(\begin{array}{ccc}\sum \log _{10} N_{\mathrm{e}_{1}^{\prime}}^{\prime} \cdot \log _{10} N_{\mathrm{e}_{1}^{\prime}} & \cdots & \sum \log _{10} N_{\mathrm{e}_{1}^{\prime}}^{\prime} \cdot \log _{10} N_{\mathrm{e}_{126}^{\prime}} \\ \vdots & \ddots & \vdots \\ \sum \log _{10} N_{\mathrm{e}_{126}^{\prime}}^{\prime} \cdot \log _{10} N_{\mathrm{e}_{1}^{\prime}} & \cdots & \sum \log _{10} N_{\mathrm{e}_{126}^{\prime}}^{\prime} \cdot \log _{10} N_{\mathrm{e}_{126}^{\prime}}\end{array}\right)\left(\begin{array}{c}\alpha_{1} \\ \vdots \\ \alpha_{126}\end{array}\right)$.

The $\alpha$ are calculated in each 3-dimensional bin. Finally, the modeled $N_{\mathrm{e}}$ is obtained by linearly interpolating between the bins.

\section{Results and Discussion}

In order to estimate the accuracy of the F3/C model, the root-mean-square error (RMS) is calculated as follows,

$$
\mathrm{RMS}=\sqrt{\frac{1}{n} \sum_{i=1}^{n}\left\{\left(o_{i}-m_{i}\right) / m_{i}\right\}^{2}}
$$

where $n, o_{i}, m_{i}$, denote the data number, the $N_{\mathrm{e}}$ observed with F3/C, and the $N_{\mathrm{e}}$ derived by the F3/C model, respectively. RMSs at each altitude level are displayed in Fig. 2. The RMS is over $50 \%$ below $200 \mathrm{~km}$ while the RMS decreases with increasing altitude, and shows a minimum 

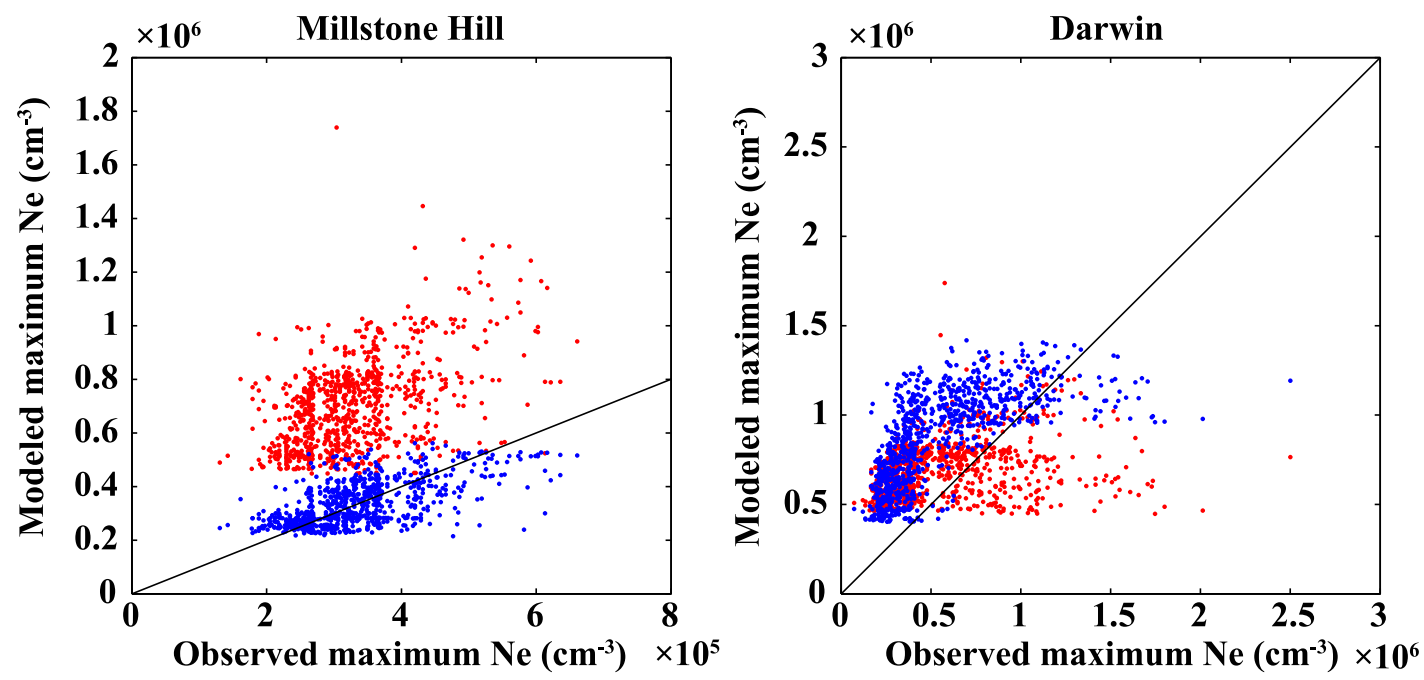

Fig. 3. Comparison of peak electron density derived by the F3/C model and the IRI model with ionosonde observations at $1200 \mathrm{LT}$ at Millstone Hill (left) and Darwin (right) from 29 June, 2006, to 17 October, 2009. Red and blue dots indicate the F3/C and the IRI model results.
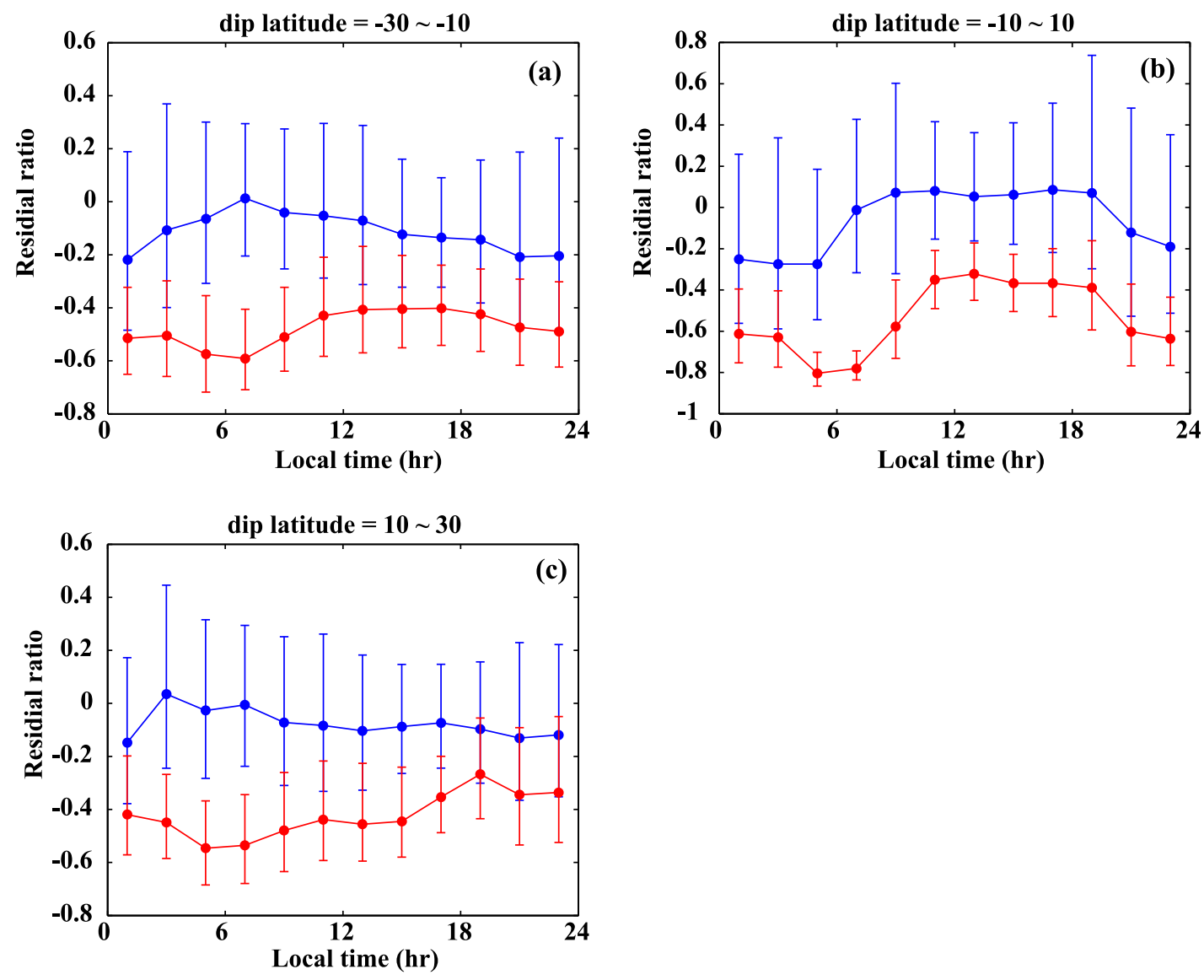

Fig. 4. Local time variation of the residual ratios for the F3/C (blue) and IRI (red) models in (a) dip latitude $=-30 \sim-10,(\mathrm{~b})$ dip latitude $=-10 \sim 10$ and (c) dip latitude $=10 \sim 30$. Dots and error bars denote median and quartiles.

value at $300 \mathrm{~km}$. The RMS increases with increasing altitude over $300 \mathrm{~km}$ and reaches about $45 \%$ around $500 \mathrm{~km}$. Below $250 \mathrm{~km}$, the estimation error of the $N_{\mathrm{e}}$ profile is very large due to the fundamental issue of the Abel inversion (Liu et al., 2010), and the data used in the construction have inherent errors. Such errors might produce a high dispersion and show high RMS. On the other hand, since a similar high variability is seen in the $N_{\mathrm{e}}$ model using the
HINOTORI data at $600 \mathrm{~km}$ (Kakinami et al., 2008), the dispersion of $N_{\mathrm{e}}$ might be high above $400 \mathrm{~km}$.

The peak $N_{\mathrm{e}}$ calculated with the F3/C model are compared with those measured with ionospondes (Millstone Hill at $71.5^{\circ} \mathrm{W}, 42.6^{\circ} \mathrm{N}$ and Darwin at $\left.131.0^{\circ} \mathrm{E}, 12.7^{\circ} \mathrm{S}\right)$ and IRI2007 with standard options (henceforth, we use the same IRI version) from 29 June, 2006, to 17 October, 2009, under geomagnetically quiet conditions, $K_{\mathrm{p}}<4$ (Fig. 3). The 


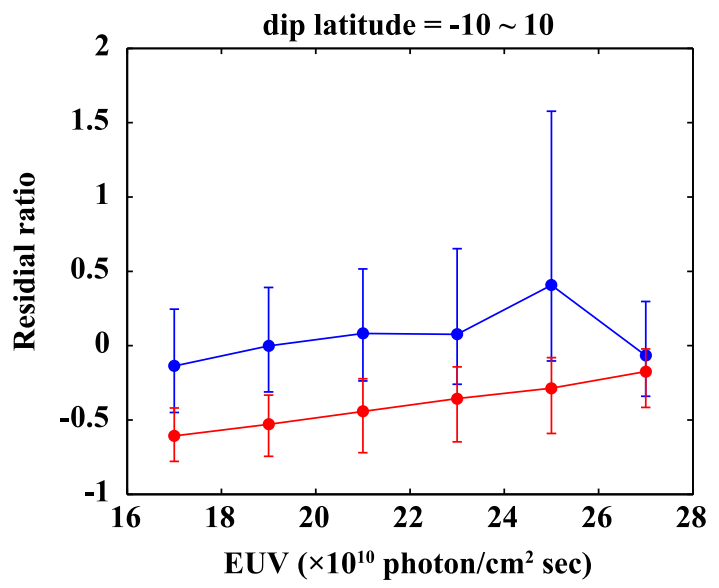

Fig. 5. Solar flux variation of the residual ratios for the F3/C (blue) and IRI models (red) in dip latitude $=-10 \sim 10$. Dots and error bars denote median and quartiles.
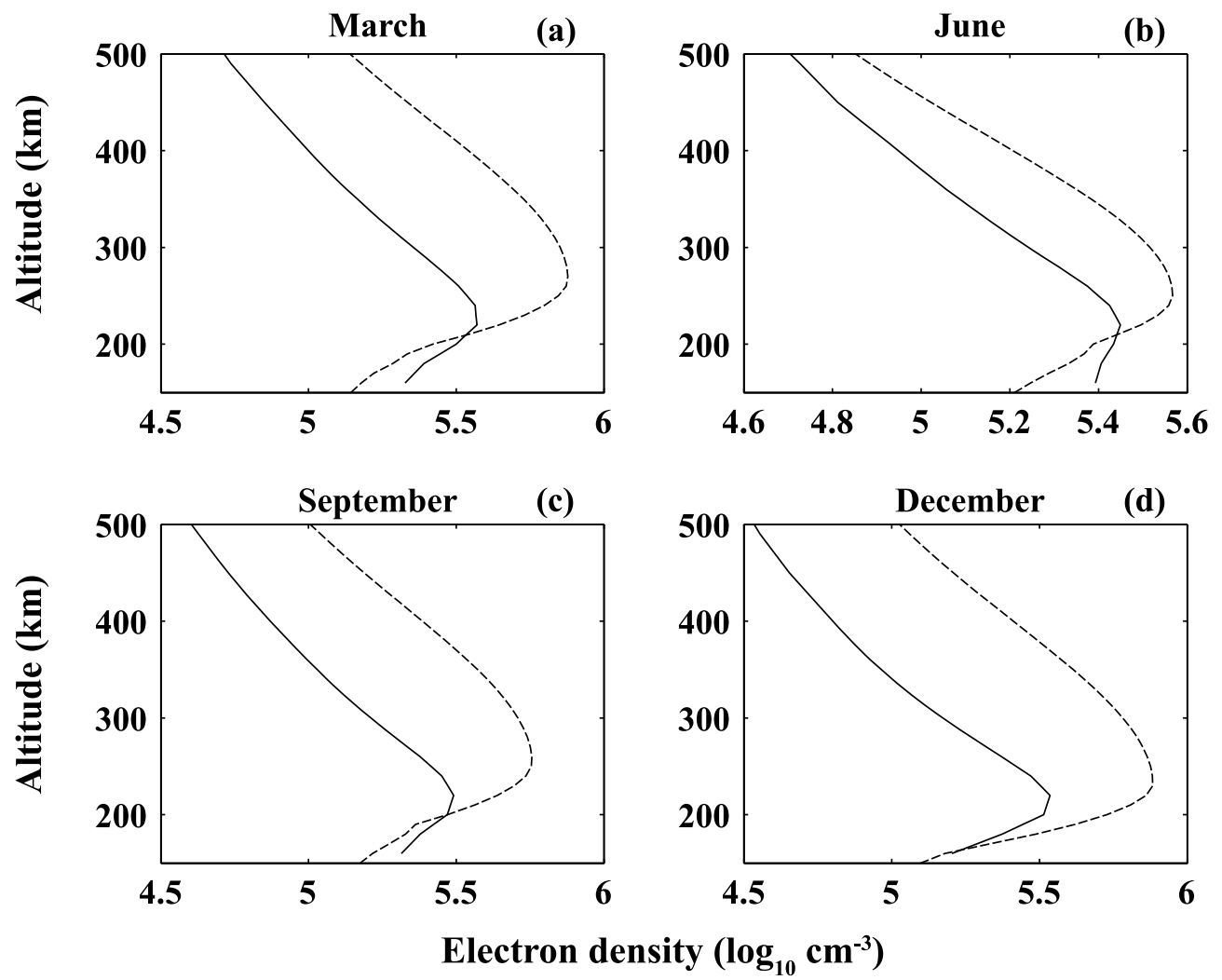

Fig. 6. Electron density profiles derived by the F3/C (solid line) and IRI models (dashed line) at $42.5^{\circ} \mathrm{N} 288.5^{\circ} \mathrm{E}$ at $1200 \mathrm{LT}$ in $\mathrm{March}$ (a), June (b), September (c) and December (d). Intensities of EUV applied to calculations are $1.99,1.99,1.84$ and $2.20 \times 10^{11} \mathrm{photon} / \mathrm{cm}^{2} \mathrm{sec}$, which are the actual conditions of solar flux in each month of 2007.

results with IRI match the observations at Millstone Hill, while those with the F3/C model overestimate the observations. Meanwhile, both models overestimate at Darwin in many cases. This result indicates that the reproduction of peak density by the IRI also has shortcomings at some locations.

In order to compare the observed $N_{\mathrm{e}}$ using F3/C with the $\mathrm{F} 3 / \mathrm{C}$ and IRI model, residual ratios, $\left(o_{i}-m_{i}\right) / m_{i}$, where $o_{i}$ and $m_{i}$ denote the observed $N_{\mathrm{e}}$ at $410 \mathrm{~km}$ and the modeled $N_{\mathrm{e}}$ at $410 \mathrm{~km}$, are calculated. Figure 4 displays the local time variation of the residual ratios for the $\mathrm{F} 3 / \mathrm{C}$ and IRI models. Though the F3/C model slightly overes- timates the observations by $10-20 \%$ during night time in all latitudes, the F3/C model agrees with the observations on the whole. However, the IRI model always overestimates observations by $40-60 \%$ at all local times and latitudes. Figure 5 shows the solar flux variation of the residual ratios for the F3/C and IRI models. The F3/C model shows a good agreement with the observations except for EUV $>24 \times 10^{10}$ photon $/ \mathrm{cm}^{2}$ sec. As shown in Fig. 1, since the data number for EUV $>24 \times 10^{10}$ photon $/ \mathrm{cm}^{2}$ $\mathrm{sec}$ is very small, the reliability of the $\mathrm{F} 3 / \mathrm{C}$ model is less than that for EUV $<24 \times 10^{10}$ photon $/ \mathrm{cm}^{2} \mathrm{sec}$. On the other hand, the IRI model overestimates the observations 

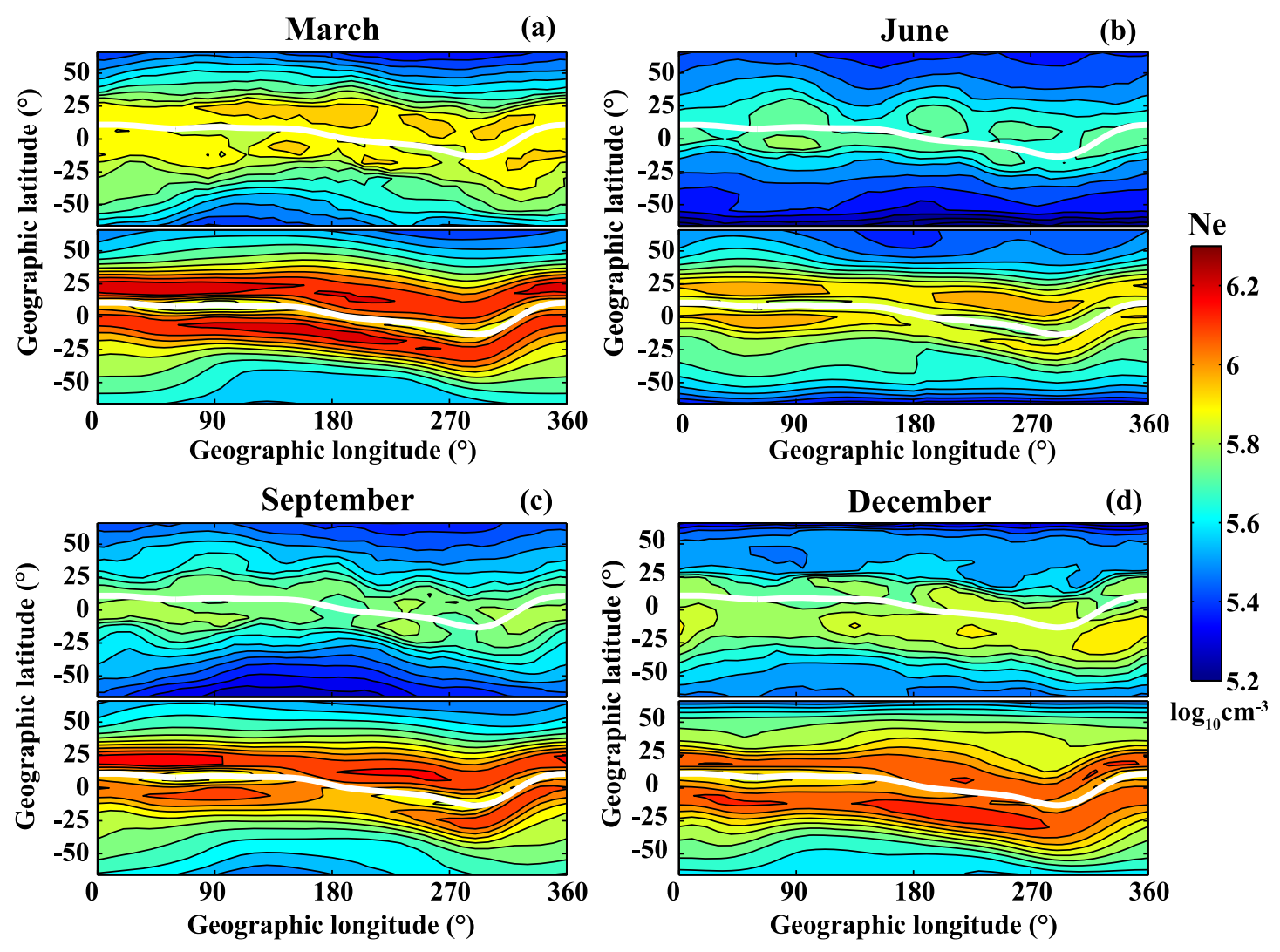

Fig. 7. Peak electron density maps derived by F3/C (top) and IRI model (bottom) at 1200 LT in March (a), June (b), September (c) and December (d). White curves indicate magnetic equator. Intensities of EUV applied to calculations are the same as Fig. 6.
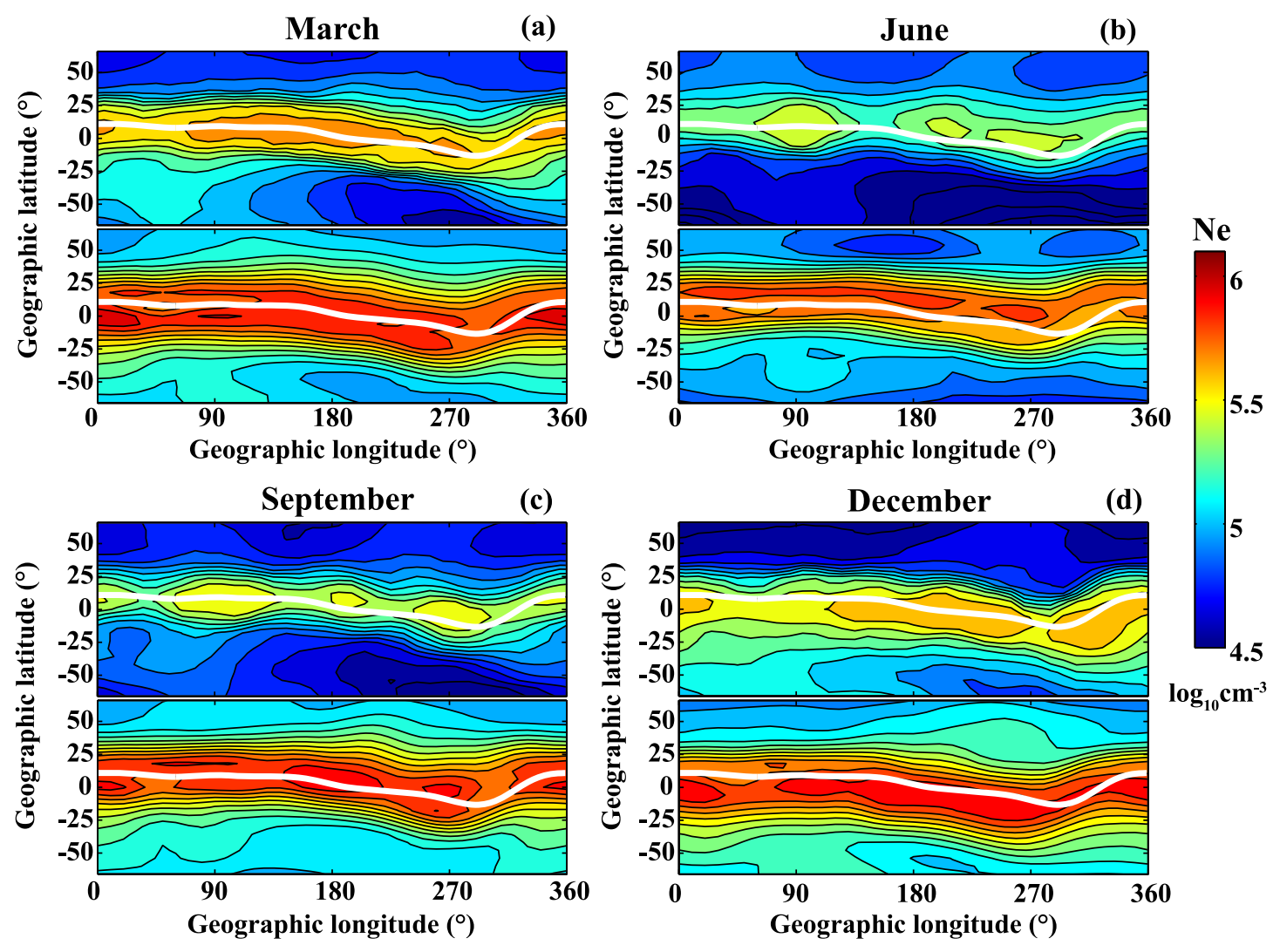

Fig. 8. Electro density maps at $450 \mathrm{~km}$ derived by F3/C (top) and IRI model (bottom) at 1200 LT in March (a), June (b), September (c) and December (d). White curves indicate magnetic equator. Intensities of EUV applied to calculations are the same as Fig. 6. 


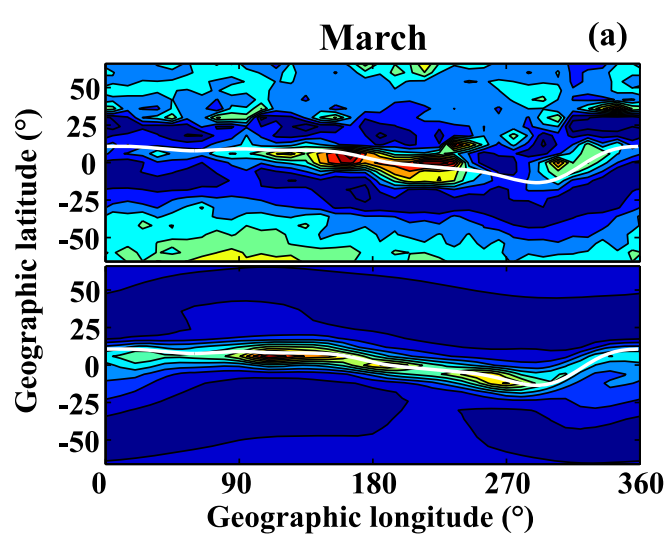

September

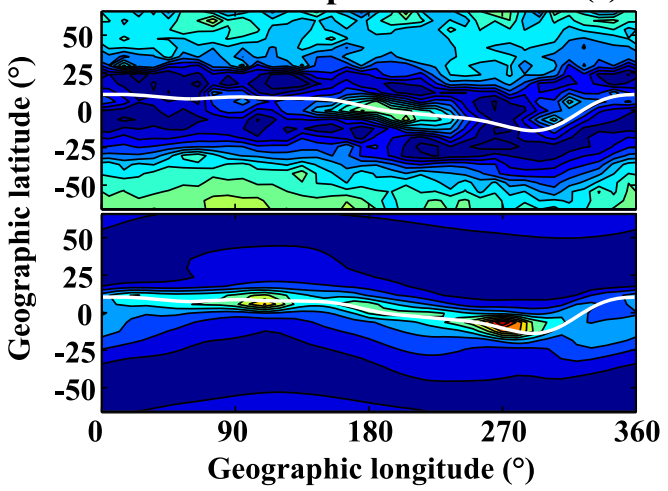

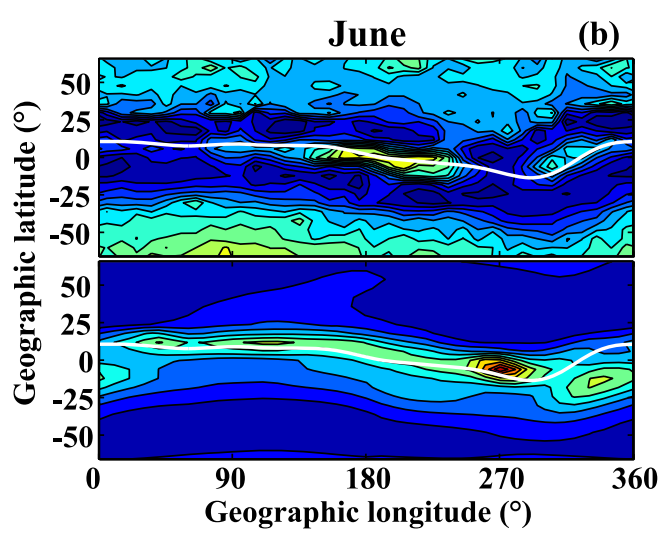

December

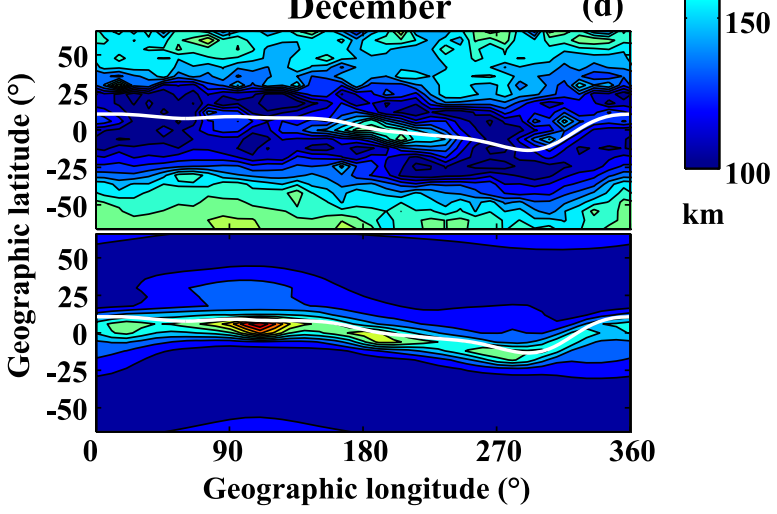

250

200

50

00

Fig. 9. Vertical scale height at $450 \mathrm{~km}$ derived by the F3/C model (top) and IRI model (bottom) at 1200 LT in March (a), June (b), September (c) and December (d). White curves indicate magnetic equator. Intensities of EUV applied in the calculations are the same as Fig. 6.

when EUV is low. The accuracy of the IRI model improves with an increase of EUV. This tendency of the IRI model to solar flux is similar to that of TEC over Taiwan (Kakinami et al., 2009).

The altitude profile of $N_{\mathrm{e}}$ derived by the F3/C and the IRI models above Inamori Hall, Kagoshima University $\left(42.5^{\circ} \mathrm{N}\right.$ $288.5^{\circ} \mathrm{E}$ ), where the IRI 2009 workshop was held, are shown in Fig. 6 . The $N_{\mathrm{e}}$ derived by the IRI model is higher than that of the F3/C model at, and above the peak height in all seasons as shown in Figs. 4 and 5. In addition, the peak altitude $h_{\mathrm{m}} F_{2}$ derived by the IRI model is higher than that of the F3/C model in all seasons. The vertical scale height (VSH) of the IRI model, which is defined as $-d h / d\left(\ln N_{\mathrm{e}}\right)$ (Kutiev et al., 2006), is slightly lower than that of the F3/C model in June. The $N_{\mathrm{e}}$ derived by IRI is lower than that of the F3/C model in the lower ionosphere in all seasons except December.

Figure 7 shows the seasonal variation of peak $N_{\mathrm{e}}\left(N_{\mathrm{m}} F_{2}\right)$ at $1200 \mathrm{LT}$ derived by the F3/C (top panel) and the IRI (bottom panel) models. The maximum of $N_{\mathrm{m}} F_{2}$ is located beside the magnetic equator for both models. $N_{\mathrm{m}} F_{2}$ derived by IRI is higher than that of the $\mathrm{F} 3 / \mathrm{C}$ model in all seasons. A longitudinal structure of $N_{\mathrm{m}} F_{2}$ exists in both models. Small patch-like maxima of $N_{\mathrm{m}} F_{2}$ appear in the F3/C model, while wide-longitude-range maxima of $N_{\mathrm{m}} F_{2}$ appear in IRI in March (Fig. 7(a)). A four-peak (2-peak) longitudinal structure is detected in the F3/C (IRI) model in June. The IRI model shows a clear 2-peak longitudinal structure in September. On the other hand, the F3/C model displays a 2-peak or more small-scale longitudinal structure in September. A four or three-peak structure appears in both models in December.

The seasonal variation of $N_{\mathrm{e}}$ at $450 \mathrm{~km}$ derived by the F3/C and IRI models are shown in Fig. 8. The $N_{\mathrm{e}}$ derived by the IRI model is generally higher than that of the $\mathrm{F} 3 / \mathrm{C}$ model around the magnetic equator. In contrast to the $N_{\mathrm{m}} F_{2}$ shown in Fig. 7, a large-scale longitudinal structure, which is similarly reported by many scientists (e.g. Sagawa et al., 2005; Immel et al., 2006; Lin et al., 2007; Kakinami et al., 2011), is clearly seen around the magnetic equator in the F3/C model. According to Kakinami et al. (2011), the 4-peak structure of $N_{\mathrm{e}}$ at $660 \mathrm{~km}$ observed with the DEMETER satellite is the most pronounced in September while a 3-peak structure appears in March and December. Though the IRI model also shows a longitudinal structure, the longitudinal structure retrieved with the F3/C model is more pronounced than that of the IRI and its seasonal variation agrees with previous studies.

Seasonal variations of VSH at $450 \mathrm{~km}$ derived by the F3/C and IRI models are shown in Fig. 9. The IRI model shows a maxima of $\mathrm{VSH}$ along the magnetic equator with a $10^{\circ}$ latitude width while the $\mathrm{F} 3 / \mathrm{C}$ model only displays a small maxima of $\mathrm{VSH}$ around $140-240^{\circ} \mathrm{E}$ and $300^{\circ} \mathrm{E}$ near the magnetic equator. In the F3/C model, maxima of VSH around $140-240^{\circ} \mathrm{E}$ near the magnetic equator are always significant in all seasons, which show a maximum value in March. However, a maximum of VSH around $300^{\circ} \mathrm{E}$ is only significant in March. The longitudinal structure seen in the VSH derived by the F3/C model differs from those of $N_{\mathrm{e}}$ at $450 \mathrm{~km}$ (Fig. 8). Meanwhile, 3 or 4 maxima of VSH 
derived by the IRI model appear around the magnetic equator. The location of each peak roughly corresponds to the locations of the maximum of $N_{\mathrm{e}}$ shown in Fig. 8. A significant difference in the VSH between the F3/C and the IRI models appears in the middle latitude. The VSH derived by the IRI model only shows a maximum around the magnetic equator, a sharp drop away from the magnetic equator and is almost constant in low and middle latitudes. Meanwhile, VSH derived by the F3/C model shows maxima (minima) around magnetic equator (beside geomagnetic equator) and increases with increasing latitude in low and middle latitudes. Similar VSH results are observed not only in F3/C data (Liu et al., 2008) but also by the topside sounder onboard the Alouette and ISIS satellites (Kutiev and Marinov, 2007). Especially, VHS derived by the F3/C model higher than $50^{\circ} \mathrm{S}$ is higher than the magnetic equator in September and December.

\section{Summary}

We have constructed an empirical model based on $N_{\mathrm{e}}$ profiles observed with $\mathrm{F} 3 / \mathrm{C}$ under geomagnetically quiet conditions $\left(K_{\mathrm{p}}<4\right)$. The F3/C model derives global $N_{\mathrm{e}}$ profiles between altitudes of 150 and $590 \mathrm{~km}$ as functions of the solar EUV flux, day of year, local time and location. The $N_{\mathrm{e}}$ above the $F_{2}$ peak, and the $F_{2}$ peak altitude, derived by the $\mathrm{F} 3 / \mathrm{C}$ model is lower than those derived by the IRI. The F3/C model reproduces a longitudinal structure better than the IRI model. The F3/C model also derives $\mathrm{VSH}$ which show good agreement with measurements obtained from topside sounders onboard the Alouette and ISIS satellites. Since the F3/C model has a big advantage of greater data coverage, it helps us to understand a variety of upper ionospheric phenomenon. As a result, the F3/C model contributes an improvement over the IRI model.

Acknowledgments. This work was partially supported by the Earth Observation Research Center, Japan Aerospace Exploration Agency (Y. K.) and the National Science Council project NSC 982116-M-008-006-MY3 grant of the National Central University (Y. K. and J. Y. L.).

\section{References}

Bilitza, D., A correction for the IRI topside electron density model based on Alouette/ISIS topside sounder data, Adv. Space Res., 33, 838-843, 2004.

Bilitza, D. and R. Williamson, Towards a better representation of the IRI topside based on ISIS and Alouette data, Adv. Space Res., 25(1), 149$152,2000$.

Bilitza, D., B. W. Reinsch, S. Radicella, S. Pulinets, T. Gulyaeva, and L. Triskova, Improvements of the international reference ionosphere model for the topside electron density profile, Radio Sci., 41, RS5S15, doi:10.1029/2005RS003370, 2006.

Immel, T. J., E. Sagawa, S. L. England, S. B. Henderson, M. E. Hagan, S. B. Mende, H. U. Frey, C. M. Swenson, and L. J. Paxton, Control of equatorial ionospheric morphology by atmospheric tides, Geophys. Res. Lett., 33, L15108, doi:10.1029/2006GL026161, 2006.

Judge, D. L., D. R. McMullin, S. Ogawa, D. Hovestadt, B. Klecker, M. Hilchenbach, L. R. Canfield, R. E. Vest, R. Watts, C. Tarrio, M. Kuhne, and P. Wurz, First solar EUV irradiances obtained from SOHO by the CELIAS/SEM, Sol. Phys., 177, 161-173, 1998.

Kakinami, Y., S. Watanabe, and K.-I. Oyama, An empirical model of electron density in low latitude at $600 \mathrm{~km}$ obtained by Hinotori satellite, Adv. Space Res., 41, 1494-1498, doi:10.1016/j.asr.2007.09.031, 2008.

Kakinami, Y., C. H. Chen, J. Y. Liu, K.-I. Oyama, W. H. Yang, and S. Abe, Empirical models of Total Electron Content based on functional fitting over Taiwan during geomagnetic quiet condition, Ann. Geophys., 27, 3321-3333, 2009.

Kakinami, Y., C. H. Lin, J. Y. Liu, M. Kamogawa, S. Watanabe, and M. Parrot, Daytime longitudinal structure of electron density and temperature in the topside ionosphere observed by the Hinotori and DEMETER satellites, J. Geophys. Res., doi:10.1029/2010JA015632, 2011.

Kutiev, I. and P. Marinov, Topside sounder model of scale height and transition height characteristics of the ionosphere, Adv. Space Res., 39, 759-766, 2007.

Kutiev, I., P. Marinov, and S. Watanabe, Model of topside ionosphere scale height based on topside sounder data, Adv. Space Res., 37, 943-950, 2006.

Lei, J., S. Syndergaard, A. G. Burns, S. C. Solomon, W. Wang, Z. Zeng, R. G. Roble, Q. Wu, Y.-H. Kuo, J. M. Holt, S.-R. Zhang, D. L. Hysell, F. S. Rodrigues, and C. H. Lin, Comparison of COSMIC ionospheric measurements with ground-based observations and model predictions: Preliminary results, J. Geophys. Res., 112, A07308, doi:10.1029/2006JA012240, 2007.

Lin, C. H., W. Wang, M. E. Hagan, C. C. Hsiao, T. J. Immel, M. L. Hsu, J. Y. Liu, L. J. Paxton, T. W. Fang, and C. H. Liu, Plausible effect of atmospheric tides on the equatorial ionosphere observed by the FORMOSAT3/COSMIC: Three-dimensional electron density structures, Geophys. Res. Lett., 34, L11112, doi:10.1029/2007GL029265, 2007.

Liu, L., M. He, W. Wan, and M.-L. Zhang, Topside ionospheric scale heights retrieved from Constellation Observing System for Meteorology, Ionosphere, and Climate radio occultation measurements, J. Geophys. Res., 113, A10304, doi:10.1029/2008JA013490, 2008.

Liu, J. Y., C. Y. Lin, C. H. Lin, H. F. Tsai, S. C. Solomon, Y. Y. Sun, I. T. Lee, W. S. Schreiner, and Y. H. Kuo, Artificial plasma cave in the low atitude ionosphere results from the radio occultation inversion of the FORMOSAT-3/COSMIC, J. Geophys. Res., 115, A07319, doi:10.1029/2009JA015079, 2010.

Marinov, P., I. Kutiev, and S. Watanabe, Empirical model of O+-H+ transition height based on topside sounder data, Adv. Space Res., 34, 20212025, 2004.

Rawer, K., D. Bilitza, and S. Ramakrishnan, Goals and status of international reference ionosphere, Rev. Geophys., 16, 177-181, 1978.

Sagawa, E., T. J. Immel, H. U. Frey, and S. B. Mende, Longitudinal structure of the equatorial anomaly in the nighttime ionosphere observed by IMAGE/FUV, J. Geophys. Res., 110, A11302, doi:10.1029/2004JA010848, 2005.

Y. Kakinami (e-mail: kakinami@mail.sci.hokudai.ac.jp), J.-Y. Liu, and L.-C. Tsai 